\title{
Basic Experiment on the Heat Release Property of a Tsunami Fire Fueled by Debris and Fuel Oil Spilled on the Sea Surface Following Tsunami
}

\author{
TOMOAKI NISHINO ${ }^{1}$, HIDEKAZU SUZUKI ${ }^{2}$ and TSUNETO TSUCHIHASHI ${ }^{2}$ \\ ${ }^{1}$ Graduate School of Engineering, Kobe University \\ Rokkodai 1-1, Nada, Kobe 657-8501, Japan \\ ${ }^{2}$ General Building Research Corporation of Japan \\ Fujishirodai 5-8-1, Suita, Osaka 565-0873, Japan
}

\begin{abstract}
This paper describes an effort to model the heat release rate curve of a tsunami fire. A tsunami fire is defined as a fire that breaks out in coastal areas inundated by a tsunami following an earthquake. Tsunami fires may result in the ignition of tsunami refuge buildings. One type of tsunami fire is a fire where fuel oil spilled from tanks and an enormous amount of debris such as timber, broken houses and expanded polystyrene are burning together on the sea surface. We conducted basic combustion experiments for this type of fire using a pool with a size of $600 \mathrm{~mm}$ square where heat release rates were measured by varying the types of debris and the exposed surface areas of fuel oil. Furthermore, a model for heat release rate at the fully developed phase and time to the beginning of fire decay was proposed. The predictions of the proposed model are shown to be more conservative in comparison with the experimental data.
\end{abstract}

KEYWORDS: tsunami fire, fuel oil, Japanese cedar, expanded polystyrene, heat release rate curve model

\section{NOMENCLATURE LISTING}

$\begin{array}{clcl}A & \text { exposed surface area }\left(\mathrm{m}^{2}\right) & t_{4} & \text { start time of decay }(\mathrm{s}) \\ A^{*} & \text { apparent burning area }\left(\mathrm{m}^{2}\right) & t_{5} & \text { stop time of combustion }(\mathrm{s}) \\ C & \text { cover area }\left(\mathrm{m}^{2}\right) & T & \text { flame temperature }(\mathrm{K}) \\ D & \text { diameter }(\mathrm{m}) & W & \text { mass }(\mathrm{kg}) \\ \Delta H & \text { heat of combustion }(\mathrm{kJ} / \mathrm{kg}) & \mathrm{Greek} & \\ \Delta H_{g} & \text { heat of gasification }(\mathrm{kJ} / \mathrm{kg}) & \alpha & \text { fire growth rate }\left(\mathrm{kW} / \mathrm{s}^{2}\right) \\ k \beta & \text { extinction coefficient }\left(\mathrm{m}^{-1}\right) & \sigma & \text { Stefan-Boltzmann constant }\left(\mathrm{kW} / \mathrm{m}^{2} \mathrm{~K}^{4}\right) \\ \dot{m}^{\prime \prime} & \text { burning rate }\left(\mathrm{kg} / \mathrm{m}^{2} \mathrm{~s}\right) & \text { Subscripts } \\ \dot{Q} & \text { heat release rate }(\mathrm{kW}) & e & \text { expanded polystyrene } \\ t & \text { time }(\mathrm{s}) & f & \text { fully-developed phase } \\ t_{0} & \text { preheating time }(\mathrm{s}) & o & \text { fuel oil } \\ t_{1} & \text { start time of debris fire spread }(\mathrm{s}) & w & \text { Japanese cedar } \\ t_{2} & \text { ignition time of fuel oil }(\mathrm{s}) & \infty & \text { sufficiently-great diameter } \\ t_{3} & \text { fully-developed time }(\mathrm{s}) & & \end{array}$

\section{INTRODUCTION}

A tsunami fire is defined as a fire that breaks out in coastal areas inundated by a tsunami following an earthquake. The tsunami following the Great East Japan Earthquake (2011) caused a number of fires across several coastal prefectures in the Tohoku and Kanto areas in Japan. Although it is difficult to determine the accurate number of fires because the tsunami washed away the origins of the fire, the number of fires is assumed to be comparable to that of conventional fires due to earthquakes, which have been a serious concern in Japan [1]. A certain fraction of fires developed into conflagrations, resulting in burned-out remains over a total of 67 hectares, which is more than the 46 hectares that were covered by the fires following the Kobe Earthquake (1995) [2].

The problem of particular concern related to tsunami fires is the ignition of tsunami refuge buildings. As the coastal areas facing the Pacific Ocean are known to be susceptible to tsunamis, some public facilities with a certain height have been designated as shelters from tsunamis for local residents who may find it difficult to escape because of the long distance to high ground. Figure 1 shows photographs taken from the rooftop of a tsunami refuge building (three-story) in Kesen-numa City, Miyagi Prefecture after the Great 

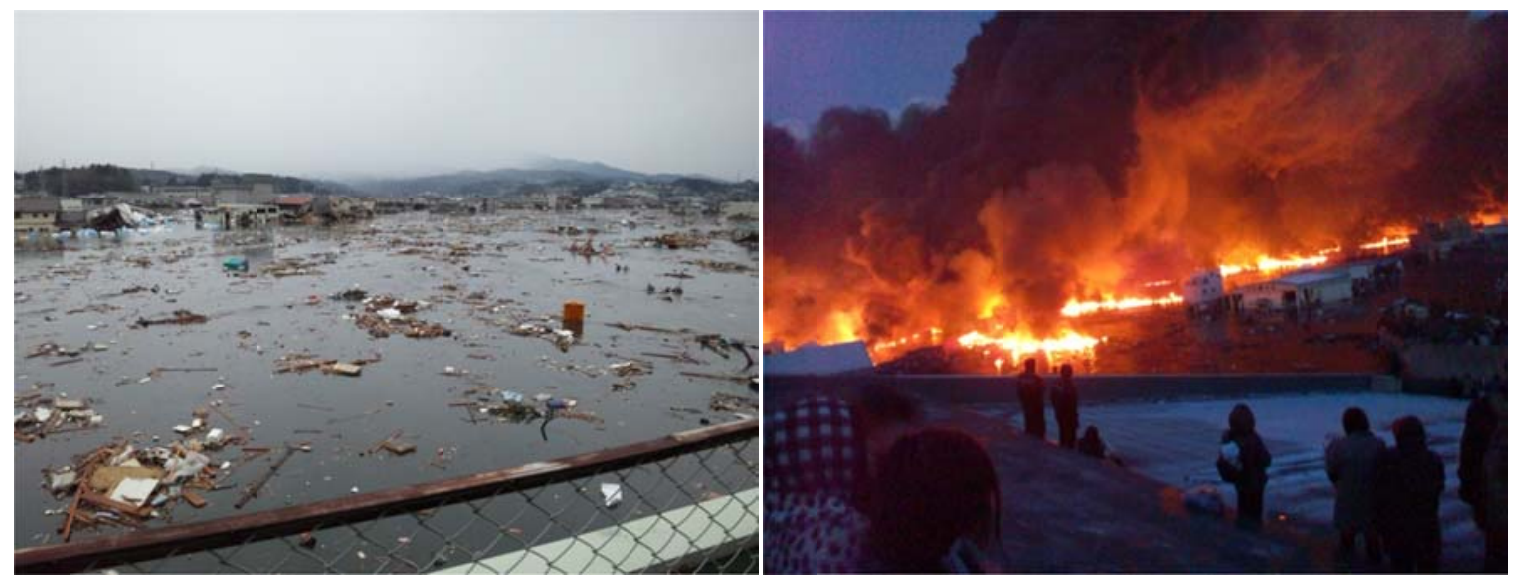

Fig. 1. Debris and tsunami fires around a tsunami refuge building after the Great East Japan Earthquake.

East Japan Earthquake. The photograph on the left indicates the debris floating on the sea surface before the conflagrations, and the photograph on the right indicates the conflagrations drifting on the sea surface. At that time, the sea surface was presumed to have been at the level of the ceiling of the second floor. Houses around the building had been washed away by the tsunami, resulting in an enormous amount of debris such as timber, broken houses and expanded polystyrene floating on seawater. The fires broke out on the sea surface approximately 3 hours after the earthquake, and some of them were drifting with large flames and plumes. According to the analysis based on image records and evacuees' testimony [3], debris and fuel oil spilled from neighboring fuel tanks were more likely to be burning together on the sea surface in these fires. If such fires drift to a tsunami refuge building and cause ignition, evacuees will be forced to remain inside the building because of the surrounding seawater and debris. However, this scenario has not been considered in the fire safety design of the building.

Adequate prediction of the heat release properties of tsunami fires is needed for evaluating the fire risk of tsunami refuge buildings. Considerable attempts [4-12] have been made to estimate the heat release properties of combustible solids and liquids. However, these attempts have separately addressed each fuel because of the difference in target fires. The properties of solid fuels such as furniture are issues for building fires [4-7] but those of liquid fuels such as oil are issues for fires in fuel tanks and on water due to oil spills [8-12]. Therefore, there is poor knowledge of fires that are caused by the combination of both fuels that occur in tsunami fires.

This paper attempts to model the heat release rate curve of a tsunami fire to make it available for the evaluation of the fire risk of tsunami refuge buildings. Basic combustion experiments for the aforementioned type of tsunami fire were conducted using a pool with a size of $600 \mathrm{~mm}$ square in a calm environment without water flow, and the heat release rates were measured by varying the types of debris and the exposed surface areas of fuel oil. Furthermore, a model for heat release rate at the fully developed phase and time to the beginning of fire decay was proposed and applied to the experiments.

\section{COMBUSTION EXPERIMENTS FOR A TSUNAMI FIRE}

\section{Experimental Concept}

Experimentally reproduced fires are required to be equal to the prototype scale to thoroughly understand the heat release properties of the tsunami fire. However, because the size of a tsunami fire is much larger than that of a typical experimental facility, it is difficult to reproduce the fire in full scale because of the environmental and economic limitations. Therefore, this study targets a portion of the fire with a size of $600 \mathrm{~mm}$ square as the first step to understand the overall properties, and it reproduces the local properties by combustion experiments where fuel dimensions are set close to the prototype without scaling down.

\section{Formulation of Heat Release Rate Curve}

Before beginning combustion experiments, we formulated the heat release rate curve of a tsunami fire. Fire safety design for buildings usually adopts fire source models in which the heat release rate increases in proportion to the square of the length of time after a preheating period, and then it reaches a maximum 
value, which is assumed to last for a given length of time [7]. We will assume that these fire source models can be applied to the tsunami fire as well.

Assuming that the outbreak of the tsunami fire is caused by a small fire source which drifts to or falls on top of floating debris, the fire is assumed to proceed according to the following scenario between debris ignition and combustion termination: (1) fire begins spreading between debris; (2) fuel oil catches fire; (3) fire becomes fully developed; (4) fire begins decaying; and (5) combustion stops. In this study, allowing the occurrence time of each event to be $t_{1}, t_{2}, t_{3}, t_{4}$ and $t_{5}$, the heat release rate of the tsunami fire $\dot{Q}$ is formulated as follows, ignoring the fire decay phase of $t_{4}$ to $t_{5}$ :

$\dot{Q}= \begin{cases}\alpha\left(t-t_{0}\right)^{2} & \left(t_{0} \leq t<t_{3}\right) \\ \dot{Q}_{f} & \left(t_{3} \leq t<t_{4}\right)\end{cases}$

where $t$ is the time, $t_{0}$ is the preheating time prior to fire growth, $\alpha$ is the fire growth rate and $\dot{Q}_{f}$ is the heat release rate at the fully developed phase.

\section{Experimental Design}

Figure 2 shows a schematic diagram of the experimental design. A fuel pool with inner dimensions of 600 $\mathrm{mm}$ square and $200 \mathrm{~mm}$ deep was built by placing calcium silicate boards with a thickness of $12.5 \mathrm{~mm}$ on the inside of steel plates. The pool was filled with water to a depth of $100 \mathrm{~mm}$, and then A-type heavy fuel oil with a density of $814 \mathrm{~kg} / \mathrm{m}^{3}$ was added to a thickness of $10 \mathrm{~mm}$ on top of the water based on the oil spill report from fuel tanks in the neighborhood that is depicted in Figure 1 [13] where 9025 kiloliters heavy fuel oil is assumed to have been diffused uniformly in 100 hectares inundated area. Note that this A-type heavy fuel oil is one type of fuel oil that is defined by Japanese Industrial Standards (JIS), and it has a property that is intermediate between normal light and heavy fuel oil because of the refining process.

Experiments were conducted under six conditions by varying the types of debris and the fuel layouts (i.e., the initial exposed surface areas of fuel oil, $A_{o}$ ). The types of debris were varied in three ways: (A) all Japanese cedar, (B) all expanded polystyrene and (C) a mixture of Japanese cedar and expanded polystyrene. The fuel layouts for each type of debris were as follows, with the initial exposed surface areas of fuel oil indicated in brackets: (A1) $5 \times 5$ arrangement $\left(0.11 \mathrm{~m}^{2}\right)$, (A2) $5 \times 1$ arrangement $\left(0.135 \mathrm{~m}^{2}\right)$, (B1) $5 \times 5$ arrangement $\left(0.11 \mathrm{~m}^{2}\right)$, (B2) $3 \times 3$ arrangement $\left(0.158 \mathrm{~m}^{2}\right)$, (C1) $5 \times 5$ staggered arrangement with expanded polystyrene in the center $\left(0.11 \mathrm{~m}^{2}\right)$ and $(\mathrm{C} 2) 3 \times 3$ arrangement of expanded polystyrene on a Japanese cedar crib with 4 rows and 2 columns $\left(0.252 \mathrm{~m}^{2}\right)$. Note that the initial exposed surface areas of fuel oil can be calculated by subtracting the area that is covered by debris on the oil surface from the pool area. In particular, the initial exposed surface area for $\mathrm{C} 2$ was calculated by considering the area that is covered by debris to be 4 sticks. The debris dimensions are indicated in Figure 2. The densities of Japanese cedar and expanded polystyrene were between 352 and $442 \mathrm{~kg} / \mathrm{m}^{3}$ (average of $391 \mathrm{~kg} / \mathrm{m}^{3}$ ) and between 9.9 and $15.2 \mathrm{~kg} / \mathrm{m}^{3}$ (average of $13.1 \mathrm{~kg} / \mathrm{m}^{3}$ ), respectively.

Considering that debris would normally be drifting on the sea surface for a length of time before ignition, all debris were made to absorb water and fuel oil before the tests by the following procedure: (1) debris were kept on the water for 30 minutes and (2) debris were maintained at the same conditions as the fuel pool for 30 minutes. The densities of Japanese cedar and expanded polystyrene after this absorption process increased to between 374 and $598 \mathrm{~kg} / \mathrm{m}^{3}$ (average of $439 \mathrm{~kg} / \mathrm{m}^{3}$ ) and between 16.5 and $26.0 \mathrm{~kg} / \mathrm{m}^{3}$ (average of $21.6 \mathrm{~kg} / \mathrm{m}^{3}$ ), respectively. The tests were started by igniting the debris bed at the center by using a torch, assuming that the burning debris drifted to or a firebrand fell on top of the floating debris. Debris movement in the fuel pool was prevented by using invar wires throughout the tests.

\section{Measurement Data}

Heat release rates were estimated at an interval of 1 second by oxygen-consumption calorimetry collecting combustion product gases through a hood with dimensions of $3500 \mathrm{~mm}$ square at a height of $2350 \mathrm{~mm}$ from the floor. In this paper, the heat release rate at the fully developed phase $\dot{Q}_{f}$ was defined as the first peak heat release rate. 
Occurrence times of events comprising the tsunami fire scenario were measured as follows: $t_{1}, t_{2}$ and $t_{5}$ were determined by visual observation, $t_{3}$ was defined as the time of the first peak heat release rate and $t_{4}$ was determined based on the transition shape. The fire growth rate $\alpha$ was estimated by the following equation:

$$
\alpha=\dot{Q}_{f} /\left(t_{3}-t_{0}\right)^{2}
$$

\section{Experimental Results and Discussion}

The experimental results are listed in Table 1 with the following conditions: debris type, debris layout, initial exposed surface area of fuel oil, occurrence times of events composing fire scenario, fire growth rate, first peak heat release rate, maximum heat release rate and total heat release. However, the ignition time of fuel oil $t_{2}$ could not be observed under conditions B1, B2, C1 and C2 because the oil surface was barely visible from underneath the flames that were formed by rapid fire spread between debris.

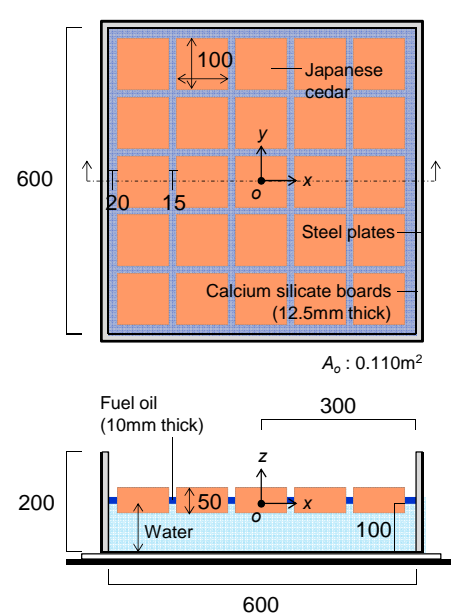

(A1) Japanese cedar, $5 \times 5$

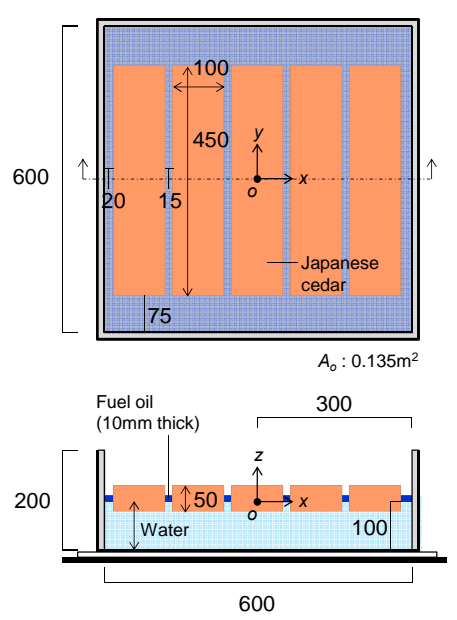

(A2) Japanese cedar, $5 \times 1$

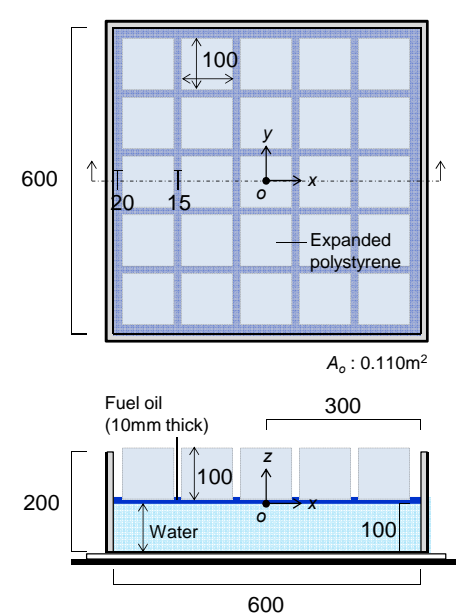

(B1) expanded polystyrene, $5 \times 5$

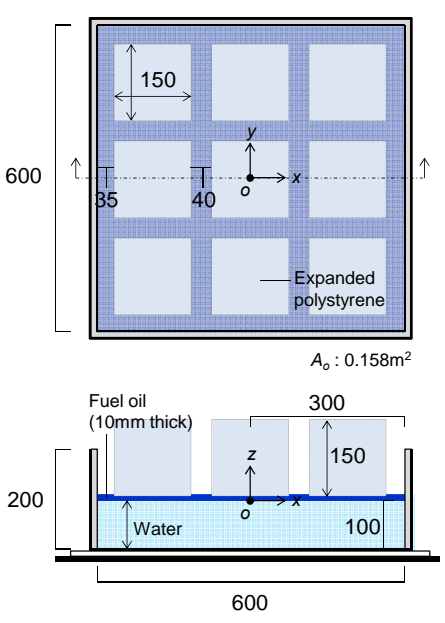

(B2) expanded polystyrene, $3 \times 3$

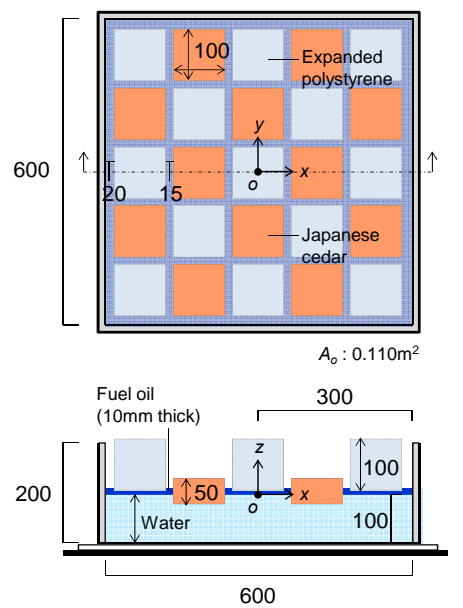

(C1) mixture, $5 \times 5$ staggered

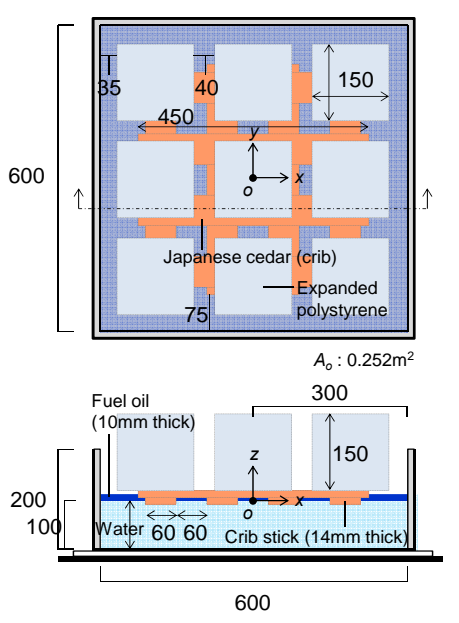

(C2) mixture, $3 \times 3$ on crib

Fig. 2. Experimental design by a combination of debris types and exposed surface areas of fuel oil (dimensions in $\mathrm{mm}$ ). 
Table 1. Overview of experimental conditions and results.

\begin{tabular}{|c|c|c|c|c|c|c|c|c|c|c|c|c|}
\hline \multirow[b]{2}{*}{ ID } & \multicolumn{2}{|l|}{ Debris } & \multirow{2}{*}{$\begin{array}{l}\text { Fuel oil } \\
A_{o}{ }^{\mathrm{d}} \\
\left(\mathrm{m}^{2}\right)\end{array}$} & \multicolumn{5}{|c|}{ Fire scenario } & \multicolumn{4}{|c|}{ Heat release property } \\
\hline & Type & Layout & & $\begin{array}{c}t_{1} \\
(\min : \mathrm{sec})\end{array}$ & $\begin{array}{c}t_{2} \\
(\min : \mathrm{sec})\end{array}$ & $\begin{array}{c}t_{3} \\
(\mathrm{~min}: \mathrm{sec})\end{array}$ & $\begin{array}{c}t_{4} \\
(\mathrm{~min}: \mathrm{sec})\end{array}$ & $\begin{array}{c}t_{5} \\
(\mathrm{~min}: \mathrm{sec}) \\
\end{array}$ & $\begin{array}{c}\alpha \\
\left(\mathrm{kW} / \mathrm{s}^{2}\right) \\
\end{array}$ & $\begin{array}{l}\dot{Q}_{f}^{\mathrm{e}} \\
(\mathrm{kW})\end{array}$ & $\begin{array}{l}\text { Max } \\
(\mathrm{kW})\end{array}$ & $\begin{array}{l}\text { THR } \\
(\mathrm{MJ})\end{array}$ \\
\hline A1 & $\mathrm{JCD}^{\mathrm{a}}$ & $5 \times 5$ & 0.110 & $18: 42$ & $76: 30$ & $94: 35$ & $115: 34$ & $139: 40$ & 0.0001 & 95.5 & 95.5 & 202.3 \\
\hline $\mathrm{A} 2$ & $\mathrm{JCD}^{\mathrm{a}}$ & $5 \times 1$ & 0.135 & $15: 45$ & $125: 17$ & $128: 56$ & $156: 56$ & $163: 15$ & 0.0022 & 106.5 & 106.5 & 129.4 \\
\hline B1 & $\mathrm{EPS}^{\mathrm{b}}$ & $5 \times 5$ & 0.110 & $0: 14$ & - & $1: 47$ & $5: 26$ & $9: 30$ & 0.0234 & 202.6 & 202.6 & 59.8 \\
\hline $\mathrm{B} 2$ & $\mathrm{EPS}^{\mathrm{b}}$ & $3 \times 3$ & 0.158 & $0: 28$ & - & $2: 00$ & $5: 32$ & $9: 25$ & 0.0204 & 172.8 & 172.8 & 52.0 \\
\hline $\mathrm{C} 1$ & $\operatorname{Mix}^{\mathrm{c}}$ & $5 \times 5$ & 0.110 & $1: 40$ & - & $4: 10$ & $9: 26$ & $21: 05$ & 0.0068 & 152.5 & 199.0 & 73.2 \\
\hline $\mathrm{C} 2$ & $\operatorname{Mix}^{\mathrm{c}}$ & $3 \times 3$ & 0.252 & $0: 47$ & - & $2: 11$ & $6: 16$ & $14: 45$ & 0.0219 & 154.4 & 219.7 & 65.6 \\
\hline \multicolumn{13}{|c|}{${ }^{\mathrm{a}} \mathrm{JCD}$ denotes debris type of all Japanese cedar } \\
\hline
\end{tabular}

\section{Fire scenario}

Figure 3 shows the event transitions of the fire scenario observed under each condition. The transitions were fastest in group $\mathrm{B}$, followed by group $\mathrm{C}$ and group $\mathrm{A}$. It is noted that $t_{1}$ and $t_{2}$ were greatly delayed under conditions $\mathrm{A} 1$ and $\mathrm{A} 2$ in comparison with the other conditions, resulting in long times to reach the fully developed phases. Checking the transitions of the measured heat release rates, the rates under conditions A1 and A2 remarkably began increasing from the ignition of fuel oil, but the other conditions from the fire spread between the debris. Therefore, we defined the preheating times $t_{0}$ as $t_{2}$ for conditions $\mathrm{A} 1$ and $\mathrm{A} 2$, but $t_{1}$ for the other conditions.

\section{Heat release rates}

Figure 4 shows the transitions of measured heat release rates with the time origin set at the preheating time $t_{0}$. The left plot indicates the heat release rate and the right plot indicates the total heat release. The experimental results showed a common trend with the heat release rate monotonically increasing and reaching a first peak. Afterwards, the rates maintained levels near the maximum for a length of time and reached second peaks before decaying. Therefore, the heat release rate curve model assumed in this study can be applied to the experimental data. The transitions of the heat release rates can be qualitatively classified into two groups: the A1 and A2 group in which the debris comprising Japanese cedar is characterized by a small heat release rate and a long fire duration, and the group of the other conditions in which the debris including expanded polystyrene is oppositely characterized by a rapid heat release rate and a short fire duration. The estimated fire growth rates $\alpha$ are indicated in Table 1 .

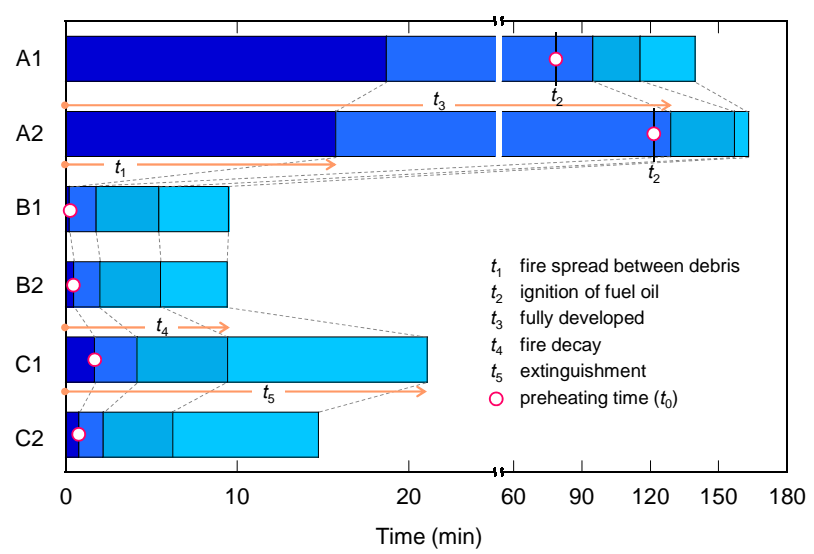

Fig. 3. Event transitions of tsunami fire scenario observed under different conditions. 

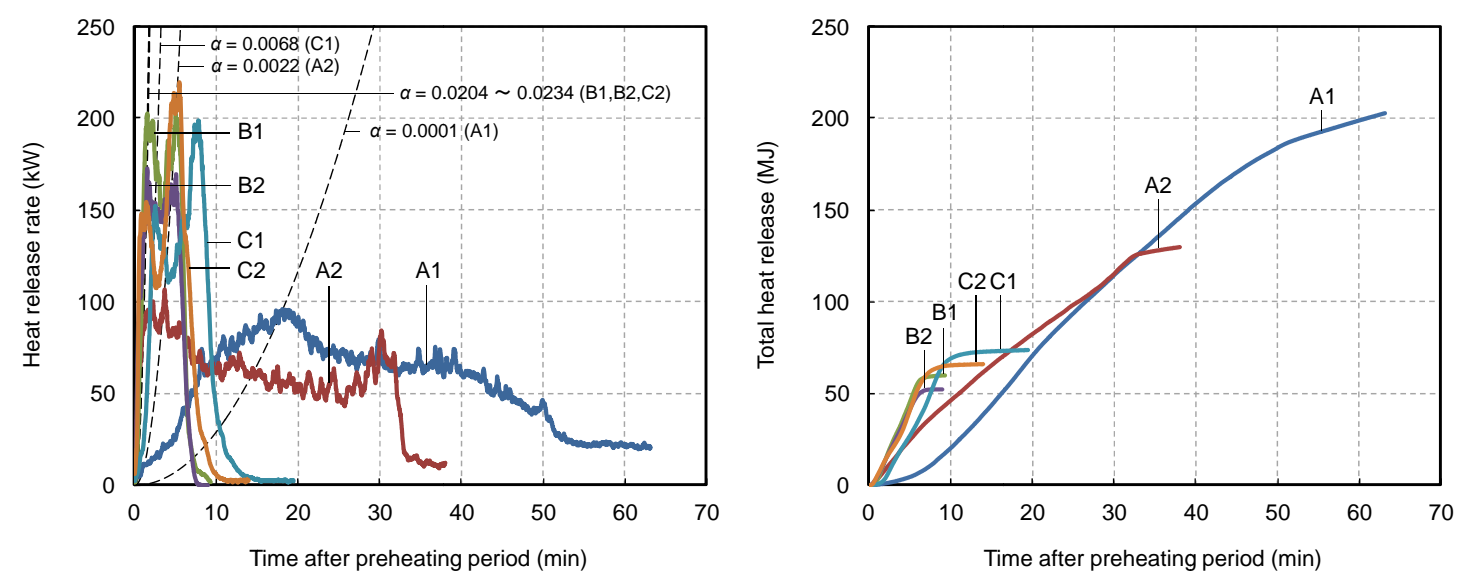

Fig. 4. Transitions of measured heat release rates after preheating period.

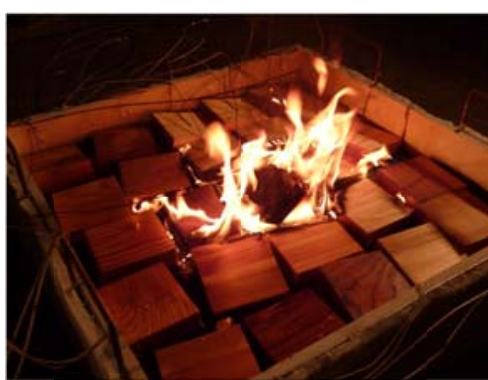

(A1) ignition of fuel oil

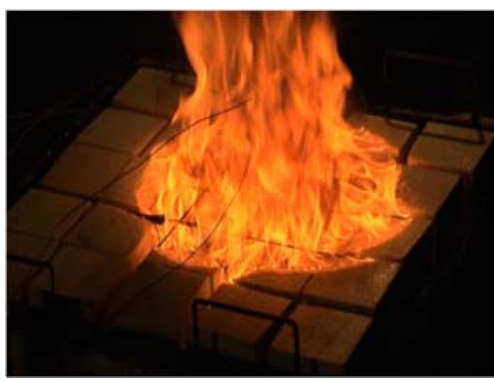

(B1) fire spread between debris

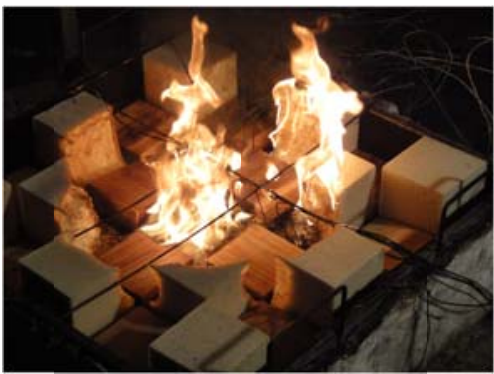

(C1) fire spread between debris

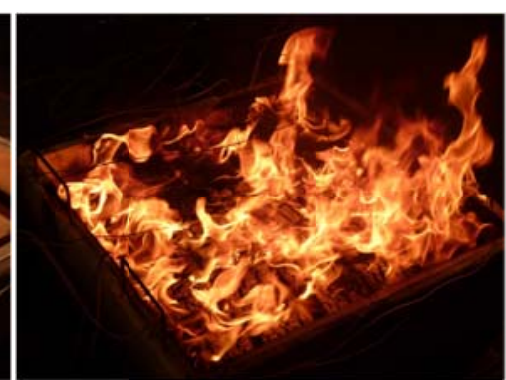

(A1) fully-developed phase

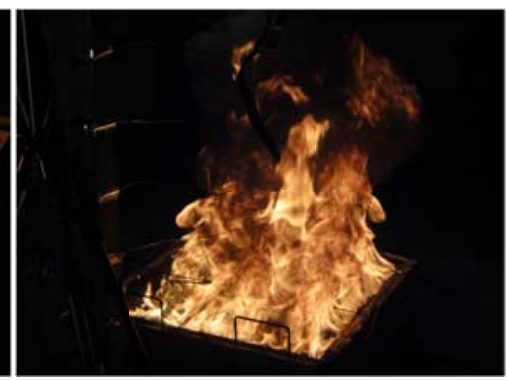

(B1) fully-developed phase

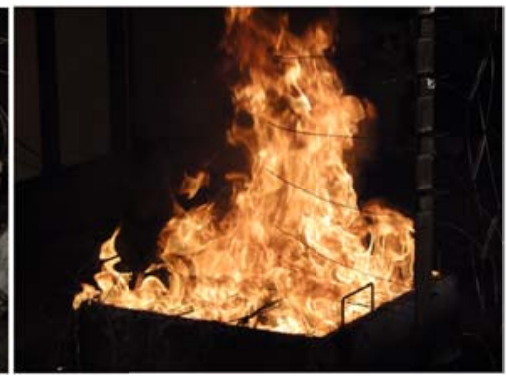

(C1) fully-developed phase

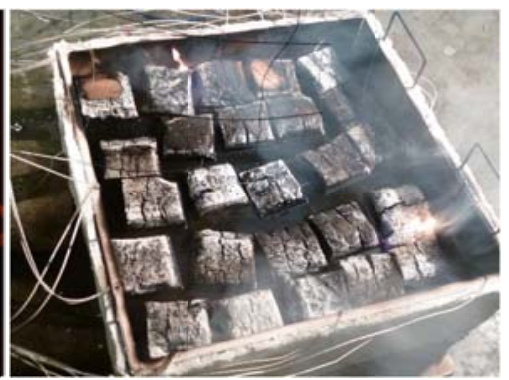

(A1) after burning

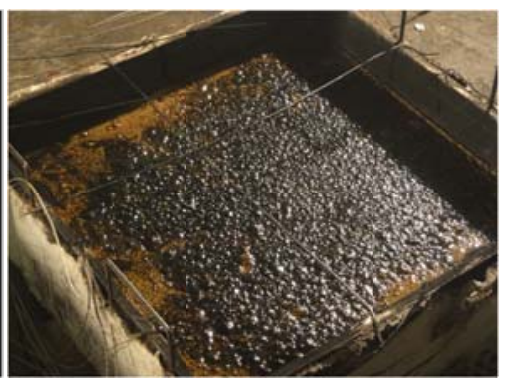

(B1) after burning

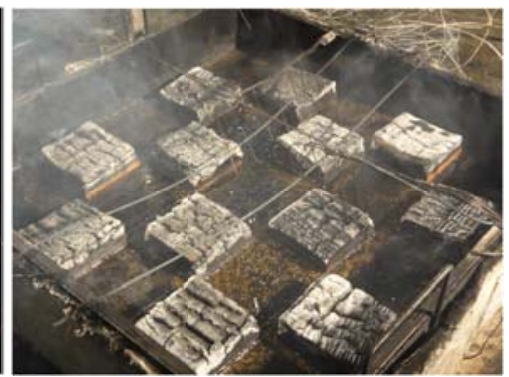

(C1) after burning

Fig. 5. Photographs taken under conditions A1, B1 and C1. 


\section{Fire aspects}

Figure 5 shows photographs taken under conditions A1, B1 and $\mathrm{C} 1$. At the fully developed phase under condition A1, the flames appeared to form from the exposed surface of the fuel oil in the spaces between the blocks of Japanese cedar. However, at the fully developed phase under conditions B1 and $\mathrm{C} 1$, the flames appeared to cover the whole area of the fuel pool because the melted expanded polystyrenes mixed with the fuel oil. Such a difference in an apparent burning area of the fuel oil depending on the types of debris might contribute to the peak heat release rate and fire duration.

Only a small amount of fuel oil remained in the pool after burning under condition A1, but all of the Japanese cedar remained with char layers. This implies the possibility that burnout of the fuel oil might stop overall combustion. Conversely, all of the initial solid fuel comprising expanded polystyrene melted under conditions $\mathrm{B} 1$ and $\mathrm{C} 1$, resulting in the pool being covered by a brown thin film after burning.

\section{Correlations}

Figure 6 shows the correlations with the initial exposed surface areas of fuel oil $A_{o}$. The left plot indicates the values of the first peak heat release rate, $\dot{Q}_{f}$ and the right plot indicates the times to the beginning of fire decay, $t_{4}-t_{0}$. These two quantities are poorly correlated with $A_{o}$ because the increase in the burning area of fuel oil due to the melting of the expanded polystyrene is not considered. To account for this effect, an apparent burning area of fuel oil $A_{o}^{*}$ can be defined as the sum of the initial exposed surface area of fuel oil $A_{o}$ and the initial area covered by expanded polystyrene on the oil surface $C_{e}$ :

$$
A_{o}^{*}=A_{o}+C_{e}
$$
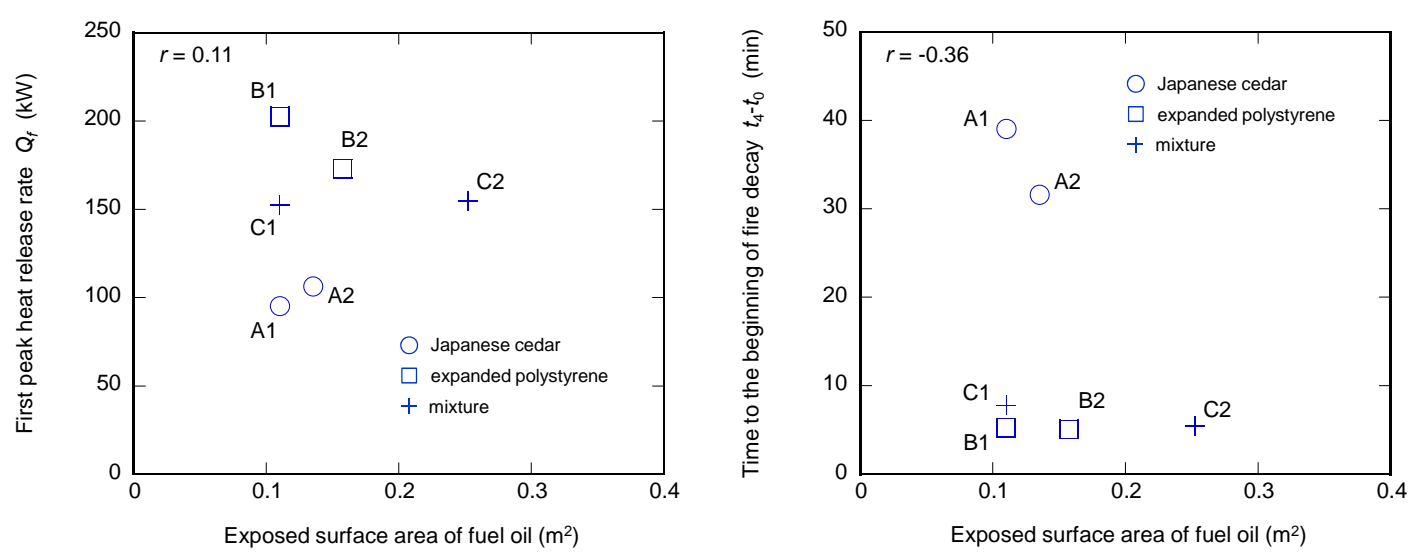

Fig. 6. Correlations of the experimental data with the initial exposed surface areas of fuel oil.
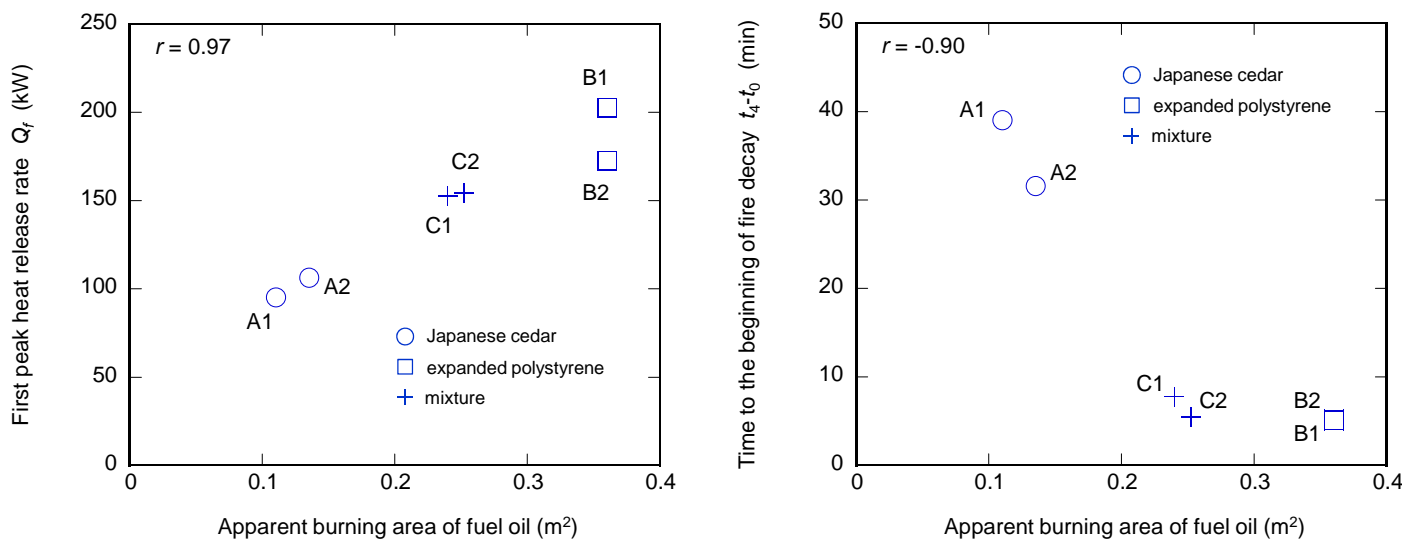

Fig. 7. Correlations of the experimental data with the apparent burning areas of fuel oil. 
A good correlation of the first peak heat release rate and the time to the beginning of fire decay with this apparent burning area of fuel oil $A_{o}^{*}$ are obtained as shown in Figure 7. The first peak heat release rates and the times to the beginning of fire decay show a positive and a negative correlation, respectively. Such a correlation implies that the fuel oil might make the dominant contribution to the overall heat release property.

\section{PREDICTABILITY OF HEAT RELEASE RATE CURVE}

Here, heat release rate at the fully developed phase $\dot{Q}_{f}$ and the time to the beginning of fire decay $t_{4}-t_{0}$ are modeled based on the assumption that the fire growth rate $\alpha$ will be explicitly given in using the model because of the difficulty in modeling. The proposed model is applied to the experiments to validate the model.

\section{Modeling}

Figure 8 shows a schematic diagram of a model for a tsunami fire at the fully developed phase. The heat release rate of the tsunami fire $\dot{Q}$ is expressed as a sum of the contributions from each fuel distributed on the water surface:

$\dot{Q}=\dot{Q}_{o}+\dot{Q}_{w}+\dot{Q}_{e}$

where $\dot{Q}_{o}, \dot{Q}_{w}$ and $\dot{Q}_{e}$ are the heat release rates of fuel oil, Japanese cedar and expanded polystyrene, respectively.

Assuming that the fully developed fire is fuel-controlled, each heat release rate is considered to be proportional to the exposed surface area of each fuel. However, this concept cannot be applied to expanded polystyrene, which mixes with fuel oil upon melting. Therefore, using the apparent burning area of fuel oil $A_{o}^{*}$ expressed as Equation 3, the heat release rates of fuel oil and expanded polystyrene are modeled as a single heat release rate of a pool fire of fuel oil without explicitly considering expanded polystyrene. Thus, the heat release rate at the fully developed phase $\dot{Q}_{f}$ is rewritten as follows:

$\dot{Q}_{f}=\Delta H_{o} \dot{m}_{o}^{\prime \prime} A_{o}^{*}+\Delta H_{w} \dot{m}_{w}^{\prime \prime} A_{w}$

where $\Delta H_{o}$ and $\Delta H_{w}$ are the heats of combustion of fuel oil and Japanese cedar, respectively; $\dot{m}_{o}^{\prime \prime}$ and $\dot{m}_{w}^{\prime \prime}$ are the burning rates per unit area of fuel oil and Japanese cedar, respectively and $A_{w}$ is the exposed surface area of Japanese cedar.

The burning rate of pool fires with diameters greater than $0.2 \mathrm{~m}$ is dominated by the effect of flame radiation [9]. Here, ignoring the other heat transfers such as convection heat and heat loss to water and pool wall, the burning rate of fuel oil $\dot{m}_{o}^{\prime \prime}$ is expressed as follows:

$\dot{m}_{o}^{\prime \prime}=\frac{\sigma T^{4}\left(1-e^{-k \beta D}\right)}{\Delta H_{g}} \quad(D>0.2)$

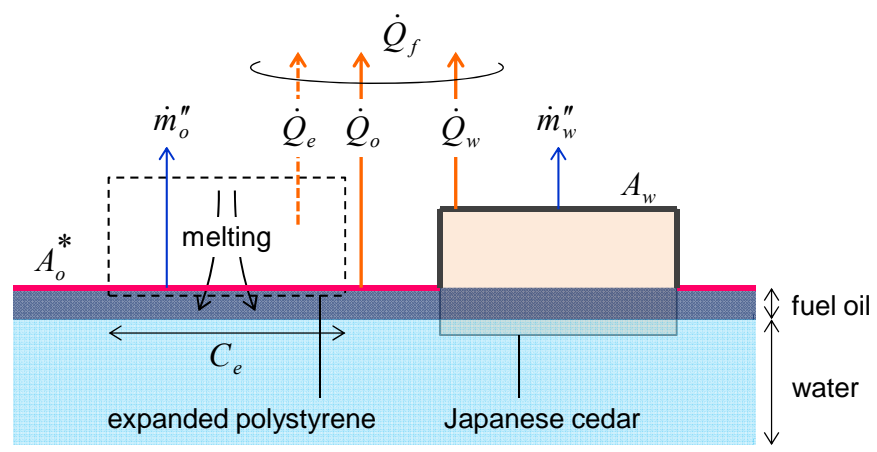

Fig. 8. Schematic diagram of a model for tsunami fire in the fully-developed phase. 
where $\sigma$ is the Stefan-Boltzmann constant, $T$ is the flame temperature, $\Delta H_{g}$ is the heat of gasification, $k \beta$ is the effective extinction coefficient and $D$ is the diameter of the fire source. Using the burning rate of pool fires with sufficiently wide diameters $\dot{m}_{o, \infty}^{\prime \prime}$, this equation can be approximated by the following function of diameter $D[10]$ :

$$
\dot{m}_{o}^{\prime \prime}=\dot{m}_{o, \infty}^{\prime \prime}\left(1-e^{-k \beta D}\right) \quad(D>0.2)
$$

The diameter $D$ is calculated by the following equation as the effective diameter of the apparent burning area of fuel oil $A_{o}^{*}$ :

$$
D=\left(\frac{4 A_{o}^{*}}{\pi}\right)^{1 / 2}
$$

If combustion stops as soon as fuel oil burns out, the time to the beginning of fire decay $t_{4}-t_{0}$ can be regarded as the time required for all fuel oil to be consumed for combustion. Therefore, assuming that the mass of fuel oil $W_{o}$ is consumed at the burning rate at the fully developed phase $\dot{m}_{o}^{\prime \prime} A_{o}^{*}$ regardless of time, the time to the beginning of fire decay $t_{4}-t_{0}$ is expressed as follows:

$$
t_{4}-t_{0}=\frac{W_{o}}{\dot{m}_{o}^{\prime \prime} A_{o}^{*}}
$$

\section{Comparison with the Experimental Data}

Figure 9 shows the comparison of the results that were predicted by the model with the experimental data, where $0.032 \mathrm{~kg} / \mathrm{m}^{2} \mathrm{~s}$ was used for the burning rate of fuel oil with sufficiently wide diameters $\dot{m}_{o, \infty}^{\prime \prime}$ based on Babrauskas's analysis of heavy fuel oil [10]. The left plot presents the comparison for the heat release rates at the fully developed phase, $\dot{Q}_{f}$ and the right plot does the same for the time to the beginning of fire decay, $t_{4}-t_{0}$. The effective extinction coefficient $k \beta$ and the heat of combustion of fuel oil $\Delta H_{o}$ were set equal to $1.1 \mathrm{~m}^{-1}$ and $39.7 \mathrm{MJ} / \mathrm{kg}$, respectively. In the case of Japanese cedar, we regarded $\Delta H_{w} \dot{m}_{w}^{\prime \prime}$ as the heat release rate per unit area and assigned it the average value $108.8 \mathrm{~kW} / \mathrm{m}^{2}$ that was obtained by the cone calorimeter tests for Japanese cedar using the same absorption process as this study under five heat flux levels of $10,15,20,30$ and $40 \mathrm{~kW} / \mathrm{m}^{2}$ [14]. However, it is difficult to accurately estimate the exposed surface area of Japanese cedar $A_{w}$ because of the variation of their inundated depth following the mass decrease throughout the tests. Therefore, we calculated $A_{w}$ on the assumption that the part to a height of 10 $\mathrm{mm}$ from the bottom surface was submerged below the liquid level.
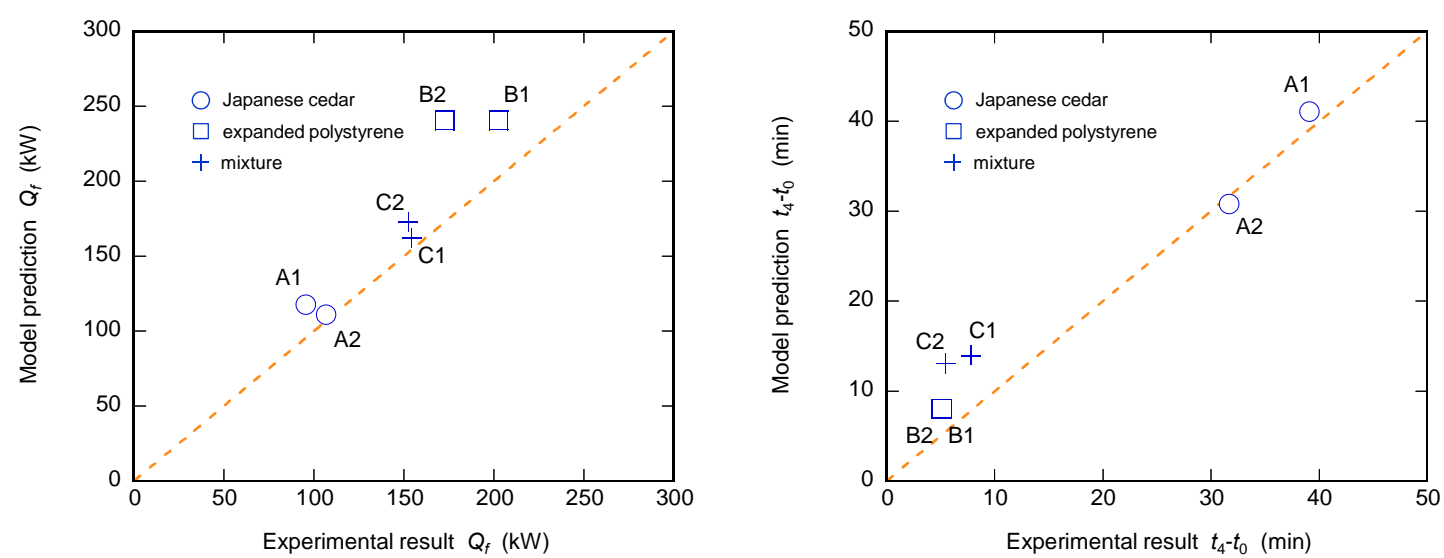

Fig. 9. Comparison of the predicted results with the experimental data. 
The predicted heat release rates had values in the range of 1.04-1.39-fold greater than those of the experimental data, resulting in conservative predictions by the model. The discrepancies, which were large under conditions $\mathrm{B} 1$ and $\mathrm{B} 2$, but small under conditions $\mathrm{A} 1, \mathrm{~A} 2, \mathrm{C} 1$ and $\mathrm{C} 2$, might be caused by ignoring heat loss to water and pool wall in formulating the burning rate of fuel oil. Similarly, the predicted time to the beginning of fire decay had conservative values, with ratios to the experimental data that were in the range of 0.98-2.38. The discrepancies, which were large under conditions $\mathrm{C} 1$ and $\mathrm{C} 2$, but small under conditions A1, A2, B1 and B2, might be caused by assuming that all fuel oil is consumed by the beginning of fire decay.

\section{CONCLUSION}

An attempt to model the heat release rate curve of a tsunami fire was made in this paper. Basic combustion experiments for a fire where debris and fuel oil are burning together on the sea surface were conducted using a $600 \mathrm{~mm}$ square pool in a calm environment without water flow. Heat release rates were measured by varying the types of debris and the initial exposed surface areas of fuel oil. Furthermore, a model for the heat release rate at the fully developed phase and the time to the beginning of fire decay was proposed by expanding the existing empirical model for the burning rate of liquid fuel and applied to the experiments to validate the model.

The obtained results are summarized as follows:

- The tsunami fire proceeded according to the following scenario between debris ignition and combustion termination: (1) fire begins spreading between debris, (2) fuel oil catches fire, (3) fire becomes fully developed, (4) fire begins decaying and (5) combustion stops.

- Allowing the preheating time to be the origin, the transitions of heat release rates could be treated similarly to the usual fire source models for building fires, which assumes that the heat release rate increases in proportion to the square of time and reaches a maximum that lasts for a given length of time.

- The transitions of the heat release rates could be qualitatively classified into two groups: the A1 and A2 group in which the debris comprising Japanese cedar is characterized by a small heat release rate and a long fire duration, but the group of the other conditions in which the debris including expanded polystyrene is oppositely characterized by a rapid heat release rate and a short fire duration.

- The fire growth rates were measured to be in the range of $0.0001-0.0234 \mathrm{~kW} / \mathrm{s}^{2}$. The rates were largest for group $\mathrm{B}$, followed by groups $\mathrm{C}$ and $\mathrm{A}$.

- $\quad$ The first peak heat release rate and the time to the beginning of fire decay were reasonably correlated with the apparent burning area of fuel oil considering the increase in burning area due to the melting of the expanded polystyrene.

- $\quad$ The proposed model yielded conservative errors in comparison with the experimental data. The ratios of model values to experimental data for heat release rates at the fully developed phase were in the range of 1.04-1.39, and those for the times to the beginning of fire decay were in the range of 0.98 2.38 .

However, the obtained results and model have only limited application to small scale fires because the experiments reproduced a local property of tsunami fires, but the proposed model has a potential applicability for the evaluation of large scale fires because the scale effect is explicitly considered as the diameter of the apparent burning area of fuel oil. Further experiments close to full scale are needed to verify the experimental results and the model's applicability to large scale fires.

\section{REFERENCES}

[1] Tanaka, T., (2012) Characteristics and Problems of Fires following the Great East Japan Earthquake in March 2011, Fire Safety Journal 54: 197-202, http://dx.doi.org/10.1016/j.firesaf.2012.07.002

[2] Survey Report on Damage and Firefighting Activity in the Great East Japan Earthquake 2011, National Research Institute of Fire and Disaster Technical Report 82, 2011, p. 41. 
[3] Nishino, T. and Hokugo, A., (2013) Case Study on the Fire due to Tsunami around a Tsunami Refuge Building based on Image Records, Bulletin of Japan Association for Fire Science and Engineering, Vol.63, No.1: 1-8.

[4] Mowrer, F.W. and Williamson, R.B., (1990) Methods to Characterize Heat Release Rate Data, Fire Safety Journal 16: 367-387, http://dx.doi.org/10.1016/0379-7112(90)90009-4

[5] Babrauskas, V. and Walton, W.D., (1986) A Simplified Characterization of Upholstered Furniture Heat Release Rates, Fire Safety Journal 11: 181-192, http://dx.doi.org/10.1016/0379-7112(86)90061-5

[6] Babrauskas, V., "Heat Release Rates," The SFPE Handbook of Fire Protection Engineering (third edition), National Fire Protection Association, 2002, pp. 3/1-37.

[7] Natori, A., Kakae, N., Kitahori, J., Tsuchihashi, T., Abe, T., Nagaoka, T., Ohmiya, Y. and Harada, K., (2006) Development of a Simple Estimation Method of Heat Release Rate based on Classification of Common Combustibles into Category Groups, Fire Science and Technology, Vol.25: 31-54.

[8] Bilnov, V. and Khudiakov, G.N., Diffusion Burning of Liquids, U.S. Army Translation, NTIS No. AD296762 (1961).

[9] Hottel, H.C., Review- Certain Laws Governing Diffusive Burning of Liquids by V.I. Bilnov and G.N. Khudiakov, Fire Research Abstracts and Reviews, Vol.1 (1958), pp.195-209.

[10] Babrauskas, V., (1983) Estimating Large Pool Fire Burning Rates, Fire Technology 19: 251-261, http://dx.doi.org/10.1007/BF02380810

[11] Chatris, J.M., Quintela, J., Folch, J., Planas, E., Arnaldos, J. and Casal, J., (2001) Experimental Study of Burning Rate in Hydrocarbon Pool Fires, Combustion and Flame 126: 1373-1383, http://dx.doi.org/10.1016/S0010-2180(01)00262-0

[12] Garo, J.P., Gillard, P., Vantelon, J.P. and Fernandez-Pello C., (1999) Combustion of Liquid Fuels Spilled on Water, Combustion Science and Technology 147: 39-59, http://dx.doi.org/10.1080/00102209908924211

[13] Damage and Response in the Great East Japan Earthquake, Fire and Disaster Management Agency, 2012, http://www.fdma.go.jp/disaster/syodokatudo_arikata_kento/03/sanko_01.pdf

[14] Suzuki, H., Nishino, T. and Tsuchihashi, T., A Study on the Burning Behavior of Tsunamiinduced Fire Part 1 -A Small Scale Fire Experiment Using Cone Calorimeter-, Annual Meeting of Japan Association for Fire Science and Engineering (2013). 